\title{
Topical ropivacaine for analgesia of aplasia cutis congenita in newborns with hereditary epidermolysis bullosa
}

\author{
A. Chambelland ${ }^{1}\left(0\right.$, C. Devos ${ }^{2}$, F. Casagrande ${ }^{3}$ and C. Chiaverini ${ }^{1 *}($ (I)
}

\begin{abstract}
Aplasia cutis congenita (ACC) in patients with hereditary epidermolysis bullosa (EB) is often associated with major pain. We report our experience with using topical ropivacaine during dressing in newborns with ACC. Eight full-term newborns with $\mathrm{EB}$ and $\mathrm{ACC}$ were hospitalized in a neonatal intensive care unit for severe pain during dressing despite the use of paracetamol, opioids $(n=8)$ or ketamine $(n=7)$. Topical xylocaine was poorly tolerated and not effective. Ropivacaine $2 \mathrm{mg} / \mathrm{ml}$ was used directly in contact with the ACC, with a maximum $1 \mathrm{mg} / \mathrm{kg} /$ day, which enabled care without the child crying. No immediate or late systemic toxicity was observed. Topical ropivacaine $0.2 \%$ appears to be an interesting topical analgesic, with good clinical tolerance and rapid action, in newborns with ACC and EB. These data need to be confirmed in a prospective study including pharmacokinetics evaluations.
\end{abstract}

Keywords: Epidemolysis bullosa, Aplasia cutis congenita, Ropivacaine, Pain, Newborn

\section{Dear editor,}

Inherited epidermolysis bullosa $(\mathrm{EB})$ is a group a rare genodermatoses characterized by skin and/or mucosal fragility leading to post-traumatic blisters [1]. Depending on the level of cleavage in the skin, four types are described: simplex, junctional, dystrophic and Kindler EB. Aplasia cutis congenita (ACC), defined by a localized absence of skin at birth, can be associated with all types of EB and is usually localized on the legs. Its exact frequency is not known but seems not negligible, up to $17.8 \%$ in patients with dystrophic forms [2]. Healing is often long with residual atrophic scar due to the atrophy of subcutaneous tissue. Management of these wounds is difficult because of severe pain during dressing changes in a complex neonatal context.

We report our experience with the use of ropivacaine in 8 full-term children (5 males), mean weight $3038.75 \mathrm{~g}$

\footnotetext{
*Correspondence: chiaverini.c@chu-nice.fr

${ }^{1}$ CRMPR Sud, Department of Dermatology, Université Côte D’Azur, CHU de Nice, Archet 2, 151 route de Saint-Antoine, 06200 Nice, France Full list of author information is available at the end of the article
}

with EB (4 simplex forms, 2 junctional, 2 dystrophic) and ACC seen in our reference center between 2010 and 2018. All newborns were hospitalized in a neonatal intensive care unit because of severe pain, feeding difficulties and complex dressing of skin wounds. Clinical data are summarized in Table 1. Despite the use of oral paracetamol, opioids $(n=8)$ or ketamine $(n=7)$ associated with non-pharmacological interventions, children still had pain during care especially on ACC areas, with inconsolable crying, permanent contraction of the face and removing of the involved limb. Two had apnea. Topical xylocaine (2\%) was poorly tolerated and not completely efficient in the first 3 children treated. We then used ropivacaine $(2 \mathrm{mg} / \mathrm{ml})$, using a syringe with a predetermined maximum dose of $0.1 \mathrm{mg} / \mathrm{kg}$ i.e. 0.25 to $0.3 \mathrm{mg}$ for babies from $2.5 \mathrm{~kg}$ to $3.4 \mathrm{~kg}=0.1$ to $0.15 \mathrm{ml}=2$ or 3 drops per dressing directly applied on the ACC surface. Due to the slight viscosity of the product, the liquid quickly recovered the wound. Treated ACC was localized in all cases in lower limbs, with a size ranging from 5 to $15 \mathrm{~cm}^{2}$ (Fig. 1). The resulting anesthesia was almost immediate 


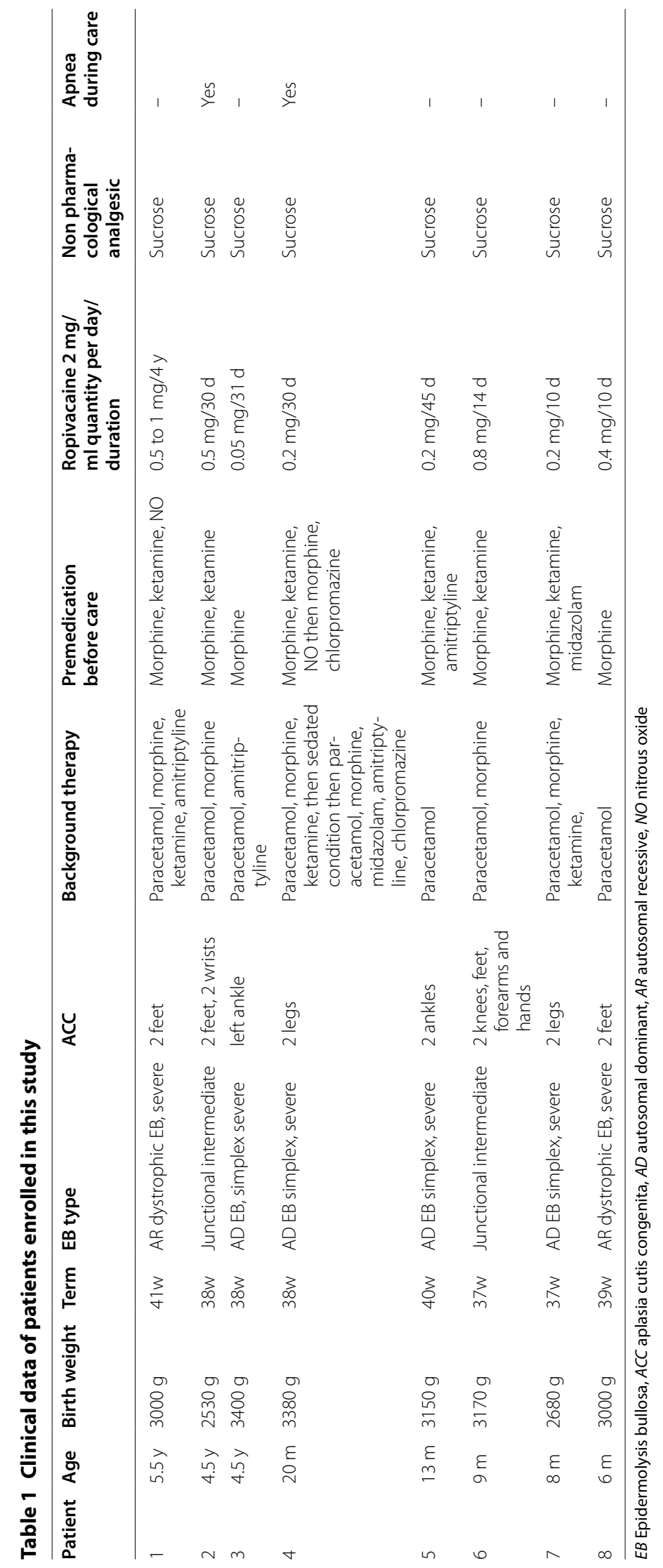




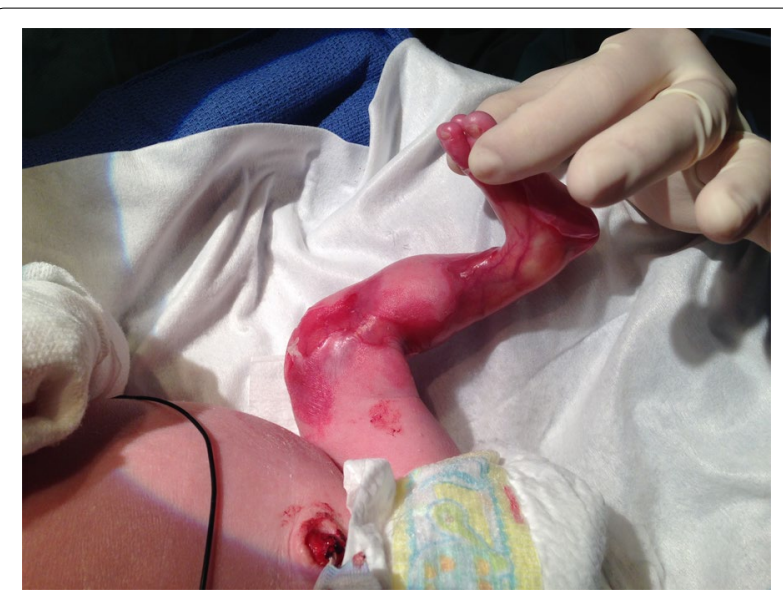

Fig. 1 Aplasia cutis congenita of the left leg in a newborn with dominant epidermolysis bullosa simplex, severe

and effective, which enabled continuing the care without the child crying, contracted face and removing limbs. The mean treatment duration was 26.7 days, with 3 dressings per week, corresponding to the time required for wound healing. No immediate allergic, cardiac, digestive or neurologic complication or late neurological systemic toxicity was observed at a median follow-up of 21.5 months (range 12-68).

Painful stimuli are stressful for infants, with mediumand long-term consequences for the brain, emotional and behavioral development. The children with ACC we describe still had localized severe pain on ACC areas during dressing despite level-3 analgesics, which led us to find an alternative topical analgesic treatment. Morphine does not provide adequate analgesia for acute procedural pain among preterm neonates [3]. Viscous lidocaine gel 2\% leads to rapid analgesia but may exacerbate pain initially. It was not well tolerated nor sufficiently effective in our first patients with ACC. Ropivacaine $0.2 \%$, applied once in direct contact with the ACC, enabled continuing the care with good analgesia without increasing systemic analgesics. Unfortunately, we did not prospectively use a specific pain score for assessing the pain before and after treatment. The DAN scale developed to assess pain during painful procedures in newborns or infants in neonatal cares seems to be relevant. It evaluates three items: facial expression, limb movement and vocal expression [4]. Retrospectively, with available clinical data, all patients had the maximal score $(10 / 10)$ before the use of ropivacaine with an improvement of at least one point of all parameters after treatment $(7 / 10)$. Ropivacaine $0.2 \%$ is usually employed for regional anesthesia in pediatric patients, including neonates and infants with a dose ranging from 0.25 to $2 \mathrm{mg} / \mathrm{kg}$ [5]. Its quick and long-lasting action (>90 $\mathrm{min}$ ) is appropriate for use during care of a dressing. Topical application of ropivacaine on mucosae has been described in adults with oral aphtosis [6] and in children after tonsillectomy to reduce postoperative pain $[7,8]$, from 5 to $10 \mathrm{mg} / \mathrm{ml}$ ( $5 \mathrm{ml} /$ surgery), while the topical use for skin analgesia is not reported. Reported side effects are: allergy, hypo or hypertension, cardiac rhythm anomalies, vomit, convulsion, urine retention, fever, hypothermia, dyspnea. With no available serum assay, we then chose a very low dose $(0.1 \mathrm{mg} / \mathrm{kg})$ to limit potential side effects and only in patients monitored in an intensive care unit. No adverse event has been observed. These retrospective findings need to be confirmed in a prospective study including pharmacokinetics evaluations.

In conclusion, topical ropivacaine $0.2 \%$ appears to be an interesting skin analgesic with good clinical tolerance and rapid analgesia in newborns with ACC and EB.

\section{Acknowledgements}

Not applicable

\section{Authors' contributions}

All authors have approved the submitted version and agreed both to be personally accountable for the author's own contributions and to ensure that questions related to the accuracy or integrity of any part of the work, even ones in which the author was not personally involved, are appropriately investigated, resolved, and the resolution documented in the literature. AC made substantial contributions to the conception of the work, the acquisition, analysis and interpretation of data and drafted the work. CD made substantial contributions to the conception of the work and had substantively revised the manuscript. CC made substantial contributions to the conception of the work, the interpretation of data and have substantively revised the manuscript. All author read and approved the final.

Funding

Not applicable.

\section{Availability of data and materials}

The datasets used and/or analyzed during the current study are available from the corresponding author on reasonable request.

\section{Ethics approval and consent to participate} Not applicable.

\section{Consent for publication}

Written informed consent was obtained from the patient's legal guardian for publication of this Letter to the Editor and any accompanying images. A copy of the written consent is available for review by the Editor-in-Chief of this journal.

\section{Competing interests}

Authors do no declare conflict of interest.

\section{Author details}

${ }^{1}$ CRMPR Sud, Department of Dermatology, Université Côte D'Azur, CHU de Nice, Archet 2, 151 route de Saint-Antoine, 06200 Nice, France. ${ }^{2}$ Department of Algology, Université Côte D'Azur, CHU de Nice, Nice, France. ${ }^{3}$ Department of Neonatal Reanimation, Université Côte D'Azur,CHU de Nice, Nice, France.

Received: 14 May 2020 Accepted: 3 November 2020

Published online: 01 December 2020 


\section{References}

1. : Consensus reclassification of inherited epidermolysis bullosa and other disorders with skin fragility. Has C. Bauer JW, C. Bodemer C, et al. Br J Dermatol. 2020. doi: https://doi.org/10.1111/bjd.18921.

2. Chiaverini C, Charlesworth A, Fernandez A, et al. Aplasia cutis congenita with dystrophic epidermolysis bullosa: clinical and mutational study. Br J Dermatol. 2014:170:901-6.

3. Suresh S, Ecoffey C, Bosenberg A, et al. The European Society of Regional Anaesthesia and Pain Therapy/American Society of Regional Anesthesia and Pain Medicine Recommendations on Local Anesthetics and Adjuvants Dosage in Pediatric Regional Anesthesia. Reg Anesth Pain Med. 2018;43:211-6.

4. Carbajal R, Lenclen R, Jugie M, Paupe A, Barton BA, Anand KJ. Morphine does not provide adequate analgesia for acute procedural pain among preterm neonates. Pediatrics. 2005;115:1494-500.

5. Carbajal R, Paupe A, Hoenn E, Lenclen R, Olivier-Martin M. DAN: une échelle comportementale d'évaluation de la douleur aigue du nouveauné. Arch Pediatr. 1997:4:623-8.
6. Gasparini G, Saponaro G, Gasparini D, et al. The use of ropivacaine in therapeutic treatment of oral aphthosis. Biomed Res Int. 2018;2018:1868254.

7. Ozkiriş M, Kapusuz Z, Saydam L. Comparison of ropivacaine, bupivacaine and lidocaine in the management of post-tonsillectomy pain. Int J Pediatr Otorhinolaryngol. 2012;76:1831-4.

8. Hong B, Lim CS, Kim YH, et al. Comparison of topical ropivacaine with and without ketamine on post-surgical pain in children undergoing tonsillectomy: a randomized controlled double-blind study. J Anesth. 2017;31:559-64.

\section{Publisher's Note}

Springer Nature remains neutral with regard to jurisdictional claims in published maps and institutional affiliations.
Ready to submit your research? Choose BMC and benefit from:

- fast, convenient online submission

- thorough peer review by experienced researchers in your field

- rapid publication on acceptance

- support for research data, including large and complex data types

- gold Open Access which fosters wider collaboration and increased citations

- maximum visibility for your research: over $100 \mathrm{M}$ website views per year

At BMC, research is always in progress.

Learn more biomedcentral.com/submissions 